\title{
Migrantes, refugiados y víctimas del tráfico de personas en el Mediterráneo (entre la política y los derechos humanos)*
}

\section{Pablo Antonio Fernández Sánchez**}

\section{RESUMEN}

En este artículo se estudian las competencias de los Estados en materia migratoria dentro de los espacios que define el derecho del mar. El análisis toma en cuenta todos los aspectos que inciden en las obligaciones de los Estados en el mar y los derechos humanos. Asimismo, se estudia el rescate de los náufragos, el derecho de las personas solicitantes de asilo, el derecho de las víctimas de tráfico de personas, bien de explotación sexual o con fines de entrada irregular en un Estado, entre otros. Igualmente, se analiza el caso concreto de los refugiados en el mar Mediterráneo, el cual merece especial atención, por su dimensión y repercusión. En este análisis, los conflictos armados, entre otro tipo de circunstancias, son la causa de la afluencia masiva de migrantes.

PALABRAS CLAVE: Espacios marinos y migraciones, migrantes en el mar, náufragos y derechos humanos, flujos masivos, refugiados en el Mediterráneo.

\begin{abstract}
This article studies the competence of the States in terms of migration in different marine spaces, as defined by the Law of the Sea. The analysis takes into consideration all aspects influencing the obligations of States in relation to the sea and human rights, as the rescue of the castaways, the right of asylum seekers and the right of victims of human trafficking. It also analyses the case of refugees in the Mediterranean Sea. Given its dimension and impact, it deserves a special attention. The causes of the mass influx of migrants considered are armed conflicts and another type of circumstances, because the consequences can be differentiated.
\end{abstract}

KEY WORDS: Marine spaces and migrations, migrants at sea, castaways and human rights, massive flows, refugee in the Mediterranean.

\footnotetext{
* Artículo recibido el 7 de diciembre de 2016 y aceptado el 10 de enero de 2017. Este trabajo se realiza en el marco del Proyecto Europeo del VII Programa Marco de Investigación "Fostering Human Rights Among European (external and internal) Policies" (Frame), Agreement 320 000, financiado por la Comisión Europea y del Proyecto de Excelencia "Las respuestas del derecho internacional y europeo a los nuevos riesgos y amenazas contra la seguridad humana" (DER2015-65906-P), en el marco de la Red de Excelencia "Nuevos desafios del derecho internacional" (DER201569273-REDT), estos últimos, ambos, financiados por el MINECO y FEDER, de la Unión Europea.

** Catedrático de Derecho Internacional Público y Relaciones Internacionales de la Universidad de Sevilla. (pafernandez@us.es)
} 


\section{SUMARIO}

1. Introducción

2. Las fronteras maritimas en relación con el control de la inmigración

3. Las obligaciones de los Estados (y de todos) relativas al rescate de los náufragos en el mar

4. Obligación de los Estados de respetar a los migrantes

5. Respuestas precarias ante la afluencia masiva de desplazados

6. Flujo masivo por causas distintas a los conflictos armados

7. Conclusiones

\section{Introducción}

En el derecho internacional, nunca se ha planteado la existencia de un derecho a emigrar, es decir, un derecho del extranjero a residir en un Estado que no es el propio. Esto hace que los Estados se hayan vuelto muy celosos en el control de las fronteras. En el marco de la Unión Europea (UE), se ha querido ir mucho más allá. Por ello, uno de los objetivos más importantes y exitosos de la Unión Europea ha sido la creación de un espacio de libertad, seguridad y justicia. Para lograr estos objetivos, el Tratado de Funcionamiento de la Unión Europea (TFUE), en sus artículos 67-89, establece las políticas europeas de control de fronteras, asilo e inmigración y la cooperación judicial y policial.

Las políticas que desarrollan estos objetivos se basan en dos garantías esenciales: en primer lugar, el respeto de los derechos humanos y las libertades fundamentales y, en segundo lugar, un alto nivel de seguridad. La primera de las obligaciones de un Estado es la protección de su seguridad territorial para garantizar la seguridad de su gente. Este es el fundamento principal del control de las fronteras.

Ahora bien, hay situaciones que no están reguladas y ello permite que los Estados, europeos especialmente, cierren las puertas a los -quizás mal llamados- refugiados, mientras critican a aquellos Estados menos desarrollados. 106 Esto sucede sobre todo con Estados de África que no pueden soportar el gasto y la presión demográfica de millones de desplazados.

Fijémonos en lo que sucede en Siria, para ilustrar mejor esta idea. Ante la violencia generalizada que se ha producido en aquel país, Turquía, Líbano, Irak y Jordania se han visto obligados a aceptar a millones de desplazados. Mientras, Europa intenta tranquilizar su conciencia pagando dinero a Turquía para que evite el flujo masivo e incesante de desplazados que llegan a nuestras sociedades ricas y cómodas. 
La UE está procediendo a bloquear sus costas, especialmente las del mar Egeo, las adriáticas y jónicas y las del Mediterráneo meridional, para impedir el acceso de los desplazados sirios, iraquíes e incluso afganos. Y cabría preguntarse si jurídicamente la Unión puede hacer eso. En principio, las obligaciones de Grecia e Italia, igual que las del resto de los Estados europeos, son muy parcas al respecto.

Puede que se estén violando normas de derechos humanos. Seguro que sí, pero no trataré de detenerme en analizar cuáles. Sin embargo, Grecia e Italia no están obligadas a recibir a los desplazados masivos, aunque por razones humanitarias lo hagan con cuentagotas.

El Alto Comisionado de las Naciones Unidas para los Refugiados ha recriminado a la UE. Sin embargo, la obliga a aceptar masivamente a los desplazados, aunque sí tiene otras obligaciones internacionales. Pero, desgraciadamente, Europa no contempla estas normas internacionales; sencillamente, no las acepta. Por lo tanto, el asilo por razones humanitarias se reconduce a la vía de la legislación general de extranjería.

Pues bien, como podemos ver, no existe una norma regional europea que obligue a aceptar a las personas que han huido de sus países porque su vida, seguridad o libertad han sido amenazadas por la violencia generalizada, la agresión extranjera, los conflictos internos, la violación masiva de los derechos humanos u otras circunstancias que hayan perturbado gravemente el orden público.

El sistema común de asilo de la uE tiene un conjunto de normas que incluye a los refugiados y a los "beneficiarios de protección subsidiaria". El estatuto de refugiado se concederá a las personas, individualmente registradas, que tienen fundados temores de persecución por las cinco razones señaladas en la Convención de Ginebra sobre el Estatuto del Refugiado de 1951, es decir, razones de raza, de religión, de nacionalidad, de pertenencia a determinado grupo social o de opiniones políticas.

El estatuto de beneficiario de protección subsidiaria se tendría que otorgar a las personas que no reúnan las condiciones para la obtención del estatuto del refugiado. Esto cuando el individuo diera motivos fundados para considerar que, si regresase a su país de origen, se enfrentaría a un riesgo real de sufrir alguno de los tres graves daños contemplados (condena a pena de muerte o su ejecución; tortura o penas o tratos inhumanos o degradantes; o la violencia indiscriminada en situación de conflicto armado internacional o interno).

Estas personas tienen derecho sobre todo a no ser forzadas a entrar, a ser conducidas o entregadas a algún país donde exista riesgo de ser sometidas a los graves daños señalados (principio de non refoulement). Y también tienen dere- 
cho a solicitar protección internacional, siempre y cuando hayan cruzado una frontera internacional y se encuentren en el territorio de un Estado miembro de la UE -incluyendo los puestos fronterizos, los espacios marinos sometidos a las competencias estatales de carácter migratorio o de seguridad marítima o se encuentren en las llamadas zonas de tránsito de un Estado miembro-.

En el marco de la UE, el Convenio de Dublín, en su versión inicial y en los reglamentos sucesivos, se limitó a homogeneizar el contenido mínimo de la Convención del 51. Esto no hacía falta dado que todos los Estados europeos son Estados parte en esta Convención.

El articulado del sistema de Dublín facilitó a los Estados el procedimiento para la determinación de qué Estado es el responsable de examinar la condición de refugiado, aunque haciéndose según cada legislación nacional. Consecuentemente, se limita a evitar a los llamados refugiados "en órbita" o a evitar las solicitudes múltiples.

Aquí y ahora nos interesa un tipo de amenaza que exige nuevos retos al derecho. Me refiero al flujo masivo de población. La primera dificultad que tendremos es la definición misma de flujo masivo. Estos términos han estado presentes en la isla italiana de Lampedusa; en las vallas, verjas o muros de Ceuta y Melilla; en las fronteras griegas, entre otras. Incluso lo hemos visto en algunas ocasiones con el acceso de cientos de inmigrantes a las costas españolas, como consecuencia de una disfunción en las relaciones hispano-marroquíes.

Cuando hablamos de las fronteras, en general, nos estamos refiriendo a las fronteras terrestres, tradicionalmente defendidas con mayor facilidad, ya sea por la existencia de accidentes geográficos, por el establecimiento de puestos fronterizos, o por la existencia de policías que controlan el acceso.

Sin embargo, el mar es un entorno donde el control es mucho más complejo. En primer lugar, esto se debe a que las competencias que el Estado puede ejercer son mucho más limitadas $\mathrm{y}$, en segundo lugar, la regulación jurídica depende de los diferentes espacios marinos en los cuales opera el Estado.

En los últimos años, el mar Mediterráneo se está convirtiendo en un gran espacio donde se libra la peor de las batallas: la lucha entre una Europa humanitaria y otra Europa segura; es decir, una tensión entre lo político y lo jurídico. Recientemente, se ve la afluencia masiva de desplazados sirios que, desde Turquía, llegan a las islas griegas del mar Egeo. Por su procedencia de un lugar donde hay un conflicto armado, no sabemos si llamarlos refugiados, asilados, acogidos o protegidos.

Por otro lado, y quizás sea la situación más dramática, miles de africanos subsaharianos llegan desde Libia a Italia, en una huida desesperada de lugares 
donde sufren hambre y baja calidad de vida. Llamamos inmigrantes a estos individuos que buscan una vida mejor. No obstante, con frecuencia son víctimas del tráfico de personas y veinte de estos migrantes mueren cada día, ahogados en el mar. ${ }^{1}$

En el contexto de este trabajo, el tráfico de personas se refiriere indistintamente al concepto clásico de trata de personas y al tráfico de migrantes. A los efectos de la Unión Europea, la consecuencia jurídica de la entrada irregular es la misma y también, como víctimas, gozan de los mismos derechos.

Es verdad que hay tratamiento jurídico diferenciado en el marco del derecho internacional, incluso en el marco del Consejo de Europa. Es más, la Unión Europea es parte en la mayoría de estos Convenios. Sin embargo, a los efectos del control de fronteras y de las consecuencias jurídicas, incluyendo los derechos de las víctimas, en este análisis se conceptualiza el tráfico de personas tal como hace la Unión Europea: indistintamente para la trata de personas como para el tráfico de migrantes.

En el marco de otros contextos, como el americano, algunos autores diferencian muy bien -sobre todo desde la perspectiva sociológica, la cual no siempre coincide con la jurídica- entre "traficantes" y "tratantes" y entre "víctimas de la trata de personas" y "víctimas del tráfico de migrantes". Incluso, en algún caso, llaman al tráfico de migrantes "contrabando de migrantes".

Propongo profundizar en el marco jurídico del control europeo de las fronteras en el mar. Para ello se considera el derecho del mar, especialmente el control de las migraciones en dos espacios diferentes: los espacios marinos en virtud de la competencia exclusiva del Estado y de los espacios marinos de competencias compartidas o internacionales.

Por otra parte, este análisis concibe las obligaciones de los Estados en relación con el derecho internacional humanitario (DIH), los derechos humanos, el derecho de asilo, la prevención del tráfico criminal de seres humanos y la necesidad del Estado de controlar sus fronteras.

Voy a analizar el punto de vista jurídico de la afluencia masiva de migrantes por mar, con el deficiente sistema de la UE para la protección temporal y las obligaciones internacionales para la protección del ser humano en el mar, teniendo en cuenta tanto el papel de la UE como el de los Estados.

El necesario refuerzo de los controles fronterizos de la UE no debe impedir el acceso a los sistemas de protección. La obligación de no devolución, un

\footnotetext{
1 Ordaz, Pablo, "Casi 3000 migrantes han muerto este año en el Mediterraneo", El País, 26 de julio, 2016. Disponible en: http://internacional.elpais.com/internacional/2016/07/22/actualidad/1469184421_996319.html
} 
principio jurídico del derecho internacional ya consagrado en el artículo 19 de la Carta de los Derechos Fundamentales de la UE no se plantea sólo cuando una persona está dentro del territorio de un Estado o en sus fronteras, sino también cuando una persona está bajo su jurisdicción de facto aunque sea fuera de su territorio, incluyendo alta mar y otros espacios marinos.

A este respecto, la Unión Europea podría instar a la inclusión de garantías de protección en las medidas de control de la inmigración, en particular, el desarrollo de un programa de entrenamiento de la guardia de fronteras, la garantía de determinación de asilo en el curso de una operación de Frontex, entre otras.

El enfoque metodológico es jurídico-sociológico, ya que junto a los aspectos jurídicos, están los aspectos políticos, diplomáticos y económicos, la combinación de los intereses nacionales, europeos e internacionales que pueden justificar las normas existentes y su aplicabilidad.

\section{Las fronteras marítimas en relación con el control de la inmigración}

En el marco del derecho del mar, podemos encontrar dos espacios donde todos los poderes del Estado, incluidos los derivados del control migratorio, pueden ejercerse: las aguas interiores y el mar territorial. Es importante entender el concepto de aguas interiores porque, en primer lugar, la ley aplicable a estas aguas es la misma que en el área de la tierra a todos los efectos. Por lo tanto, todos los derechos soberanos del Estado pueden ser ejercidos, con excepción del debido derecho de paso inocente, de acuerdo con el artículo 8.2 de la Convención de las Naciones Unidas del Derecho del Mar.

En segundo lugar, es muy importante el espacio donde se empieza a medir el mar territorial y el resto de los espacios marinos, porque, a veces, estas distancias afectan sustancialmente a la resolución de los conflictos de competencia relacionados con la interceptación de los buques que transportan inmigrantes irregulares o se involucran en el tráfico.

Dentro de esta aguas interiores, el Estado puede ejercer plenamente sus facultades jurídicas, y pueden ser ejercidas de forma exclusiva (el Estado ejerce sus funciones y actividades exclusivamente sin dar opción a otro Estado que pueda ejercer su control sin el consentimiento previo) e inviolable (el Estado tiene derecho a que otros Estados respeten su soberanía y su integridad territorial).

En relación con el mar territorial, el artículo 2 de la Convención de las Naciones Unidas sobre el Derecho del Mar establece la distancia máxima de 
12 millas, $^{2}$ aunque esta distancia puede ser menor, y se cuenta desde la línea imaginaria donde terminan las aguas interiores. Es un principio de derecho internacional general, oponible erga omnes. ${ }^{3}$

Por lo tanto, los Estados ribereños ejercen plenamente sus derechos soberanos con una excepción. Como dice Yturriaga Barberán, incluyendo la propia Convención, "tanto las reglas habituales como las convencionales del derecho internacional prevén una limitación en el ejercicio de la soberanía del Estado ribereño, reconociendo el derecho de paso inocente de todos los buques por el mar territorial". ${ }^{4}$

El derecho de paso inocente consiste únicamente en la navegación, de forma rápida y continua, si bien el artículo 18 de la Convención señala lógicamente que "el paso comprende la detención y el fondeo, pero sólo en la medida en que constituyan incidentes normales de la navegación o sean impuestos por fuerza mayor o de emergencia o con el fin de prestar auxilio a personas, buques o aeronaves en peligro o dificultad grave".

Con respecto a los problemas de la inmigración, la Convención establece en el artículo 19 que:

1. El paso es inocente mientras no sea perjudicial para la paz, el buen orden o la seguridad del Estado ribereño. Ese paso se efectuará con arreglo a esta Convención y otras normas del derecho internacional.

2. Se considerará que el paso de un buque extranjero es perjudicial para la paz, el buen orden o la seguridad del Estado ribereño si ese buque realiza, en el mar territorial, alguna de las actividades que se indican a continuación [...]

(g) El embarco o desembarco de cualquier producto, moneda o persona, en contravención de las leyes y reglamentos aduaneros, fiscales, de inmigración o sanitarios del Estado ribereño [...]

(l) Cualesquiera otras actividades que no estén directamente relacionadas con el paso.

\footnotetext{
${ }^{2}$ El artículo 3 de la Convención establece lo siguiente: "Todo Estado tiene derecho a establecer la anchura de su mar territorial hasta un limite que no exceda de 12 millas medidas a partir de las líneas de base determinadas de conformidad con esta Convención".

${ }^{3}$ Pastor Ridruejo, José Antonio, Curso de Derecho Internacional Público y Organizaciones Internacionales, Madrid, Tecnos, 2003, p. 346.

${ }^{4}$ Yturriaga Barberán, José Antonio De, Ámbitos de soberanía en la Convención de las Naciones Unidas sobre el Derecho del Mar: Una perspectiva española, Madrid, Ministerio de Asuntos Exteriores, 1993, p. 161.
} 
Como podemos ver, entre las consideraciones de lo que no es inocente, se incluyen el embarque y desembarque de personas en violación de la ley y los reglamentos de inmigración. Puesto que el paso de buques extranjeros, cualquiera que sea su cabotaje o Estado del pabellón, por el mar territorial establecidas por cada Estado, con un límite máximo de 12 millas debe ser inocente, es decir, "que no sea perjudicial para la paz, el buen orden o la seguridad del Estado ribereño".

Hay una serie de actividades que, si se realizan, el paso de los buques no es inocente y, por lo tanto, el Estado puede y debe impedir su paso. El artículo 25.1 de la Convención establece que "El Estado ribereño podrá tomar en su mar territorial las medidas necesarias para impedir todo paso que no sea inocente”. El artículo 21.1 dice:

1. El Estado ribereño podrá dictar de conformidad con las disposiciones de esta Convención y otras normas de derecho internacional, leyes y reglamentos, relativos al paso inocente por el mar territorial sobre todas o algunas de las siguientes materias [...]

(h) la prevención de infracciones de sus leyes y reglamentos aduaneros, fiscales, de inmigración y sanitarias.

Por lo tanto, todas estas actividades pueden hacer perder la inocencia del pasaje en el mar territorial. Más allá de las 12 millas de mar territorial, el primer espacio que debe tenerse en cuenta a los efectos de analizar los casos de inmigración es la zona contigua. De acuerdo con el artículo 33 de la Convención:

1. En una zona contigua a su mar territorial, designada con el nombre de zona contigua, el Estado ribereño podrá tomar las medidas de fiscalización necesarias para:

a) Prevenir las infracciones de sus leyes y reglamentos aduaneros, fiscales, de inmigración o sanitarios que se cometan en su territorio o en su mar territorial;

b) Sancionar las infracciones de esas leyes y reglamentos cometidas en su territorio o en su mar territorial.

2. La zona contigua no podrá extenderse más allá de 24 millas marinas contadas desde las líneas de base a partir de las cuales se mide la anchura del mar territorial. 
Por lo tanto, uno de los aspectos más importantes de esta zona contigua es el control de la inmigración. De esta manera, se pueden configurar los controles deseados en la zona del mar territorial, así como los controles que permite la Convención sobre el Derecho del Mar, en el área de la zona contigua.

Incluso, hay algunos acuerdos internacionales realizadas en el marco universal de las Naciones Unidas, tales como la Convención de las Naciones Unidas contra la Delincuencia Organizada Transnacional y el Protocolo para prevenir, reprimir y sancionar la trata de seres humanos, especialmente mujeres y niños y el Protocolo contra el tráfico ilícito de migrantes por tierra, mar y aire. La aplicación de éstos requeriría ciertos controles en las aguas adyacentes a los Estados del litoral, como veremos más adelante.

El punto 7 del artículo 8 del Protocolo contra el tráfico ilícito de migrantes por tierra, mar y aire afirma a este respecto que los Estados parte que tengan fundadas razones para sospechar que una embarcación está involucrada en el tráfico de migrantes por mar y no posee nacionalidad, o se hace pasar por un buque sin nacionalidad, podrá visitar y registrar el buque. Si se hallan pruebas que confirmen la sospecha, ese Estado parte adoptará medidas apropiadas de conformidad con el derecho interno y el derecho internacional.

Por el contrario, hay más limitaciones en alta mar, al ser un espacio marítimo gobernado por el principio de la libertad. En consecuencia, ningún Estado podrá ejercer más competencias en este ámbito que las autorizadas por el derecho internacional, tales como la jurisdicción exclusiva sobre los buques que enarbolen su pabellón, salvo disposición en contrario por el derecho internacional.

En relación con el tráfico ilícito de personas, podríamos hablar del derecho de persecución. Sin embargo, la primera regla es que esto debe hacerse en caliente y cuando el buque en cuestión proviene de las aguas interiores, el mar territorial o la zona contigua del Estado costero perseguidor. El cese de la persecución se llevará a cabo en el momento en que el buque se encuentre en las aguas territoriales de otro Estado o en las aguas del Estado de su pabellón.

Por supuesto, cuando el buque se encuentra en la zona contigua se puede perseguir solamente cuando se produzca una violación de las normas relacionadas con las competencias del Estado en esta área, incluyendo la inmigración, obviamente.

Convemar no estableció normas similares a la piratería o la trata de esclavos en este tipo de tráfico, ni siquiera en el tráfico de estupefacientes o de sustancias psicotrópicas. El artículo 108 incluye únicamente la obligación de cooperar en esta lucha; pero en cualquier caso esta obligación no es una obligación de resultado, sino de comportamiento y, por tanto, es muy débil. 
En este sentido, tendría que pedir el consentimiento del Estado del pabelón para inspeccionar, detener o castigar a un buque extranjero en alta mar, por el tráfico ilícito. Hoy en día, en alta mar sólo es posible la persecución en caliente, salvo las excepciones que más adelante serán expuestas.

Juan Santos Varas ha indicado que la consecuencia lógica es que el Estado que haya hecho uso de su derecho pueda ejercer la jurisdicción penal en relación con los delitos cometidos, ya que tal acción no viola la soberanía de ningún Estado y, si tal acción no fuera así, se mantendría sin castigo. ${ }^{5}$

\section{Las obligaciones de los Estados (y de todos) relativas al rescate de los náufragos en el mar}

La cuestión de salvamento marítimo es algo diferente. El primer deber prioritario del Estado es rescatar a los náufragos. En este sentido, las Naciones Unidas han dicho que el hecho de que algunas cuestiones de seguridad se centren en la supresión de la actividad criminal, ello no debe suprime la obligación, al amparo del derecho del mar y de la tradición marítima, de rescatar a los que peligran en el mar. ${ }^{6}$

Precisamente esta precariedad de la vida humana en la gran masa azul de los mares y océanos propició que el derecho internacional construyera un corpus juris para proteger la vida humana en el mar. Esta protección se inicia con la Convención Internacional para la Seguridad de la Vida Humana en el Mar (en adelante, Solas), de 1974, y continúa con la Convención Internacional sobre Búsqueda y Salvamento (SAR), de 1979.

Se requiere que los Estados europeos ribereños del Mediterráneo, todos los buques que naveguen por la zona, y especialmente los Estados Parte en esta Convención, vayan en ayuda de los buques en peligro. Así, todos los Estados europeos han delimitado las regiones de búsqueda y salvamento de los que son responsables.

El órgano encargado del seguimiento de estas cuestiones es la Organización Marítima Internacional, organismo especializado de las Naciones Unidas responsable de la seguridad en el mar y la seguridad de la navegación. La Convención SAR ha sido enmendada en relación a las personas en peligro en el mar.

\footnotetext{
${ }^{5}$ Santos Vara, Juan, "Crónica sobre la Aplicación Judicial del Derecho Internacional Público (enero-junio 2006)", ReEl, vol. 12, 2006, p. 7.

${ }^{6}$ Naciones Unidas, Guías Legislativas para la aplicación de la Convención de las Naciones Unidas contra la Delincuencia Organizada Transnacional y sus Protocolos, Estados Unidos, United Nations Publications, 2005, p. 396.
} 
Estas enmiendas fueron adoptadas en mayo de 2004 y entraron en vigor el 1 de julio de 2006.

Ahora bien, si un Estado sospecha que un barco con una bandera en particular se dedica al tráfico de seres humanos, debe buscar la cooperación del Estado del pabellón, de conformidad con el Protocolo contra el tráfico ilícito de migrantes por tierra, mar y aire y los límites que han sido identificados en el análisis de la zona contigua. Es decir, los migrantes deben solicitar permiso para visitar y registrarse y, una vez autorizados, hacerlo en las condiciones establecidas de conformidad con las responsabilidades que se puedan aplicar.

La UE ha establecido acuerdos con casi todos los países del Mediterráneo que, aun siendo acuerdos generales, son la base para la cooperación marítima internacional. En este sentido, la Unión ha concluido acuerdos con República del Líbano, República Popular Democrática de Argelia, República Árabe de Egipto, Reino Hachemita de Jordania, Estado de Israel, Reino de Marruecos y República de Túnez.

En esta materia, por razones de humanidad, debemos evitar cualquier intento de objetivizar las obligaciones legales para ayudar a los náufragos en alta mar. Sin embargo, por desgracia, el derecho del mar, como conjunto de reglas construidas a lo largo de la historia con el fin de mejorar la vida en el mar, no es suficiente. ${ }^{7}$ Por ello, se han hecho normas específicas sobre el tema.

Me gustaría señalar que en relación con la ayuda de los náufragos, existe un convenio específico, el cual regula el destino de los náufragos en el marco de un conflicto armado. Me refiero a la Segunda Convención de Ginebra para Aliviar la Suerte de los Heridos, Enfermos y Náufragos de las Fuerzas Armadas en el Mar, del 12 de agosto de 1949.

Esta Convención define los náufragos desde una perspectiva muy amplia. En su artículo 12 establece que “el término 'naufragio' será aplicable a todo naufragio, sean cuales fueren las circunstancias en que se produzca, incluido el amaraje forzoso o la caída en el mar". Y continúa afirmando que "serán tratados y asistidos con humanidad por la parte en conflicto que los tenga en su poder".

Como tal, si esta es la situación en periodos de conflictos armados para los combatientes y otros, ya sean ciudadanos enemigos o no, en tiempos de paz esta obligación se hace más homogénea y horizontal. Por lo tanto, cuando un buque, independientemente de la nacionalidad o de su naturaleza, o si se trata de un buque de Estado o no, conoce la existencia de náufragos en alta mar, tiene el deber de rescatarlos y ponerlos a salvo.

\footnotetext{
${ }^{7}$ Esta institución juridica puede ser analizada desde el derecho romano y a través de la historia.
} 
Hay todo un conjunto de normas que se dedica al estudio de estas cuestiones. Cuando se trata de salvamento marítimo, la principal norma es el "Convenio para la unificación de ciertas reglas de derecho respecto de las colisiones entre buques", de 23 de septiembre de $1910 .{ }^{8}$ Éste se conoce como Convenio de Bruselas, parcialmente derogado por el Convenio de Londres de 1989, aunque todavía en vigor.

Dicha Convención establece que todo capitán está obligado, en la medida de lo posible y sin riesgo grave para su buque, la tripulación o los pasajeros, a prestar asistencia a cualquier persona, incluso a los enemigos, que están en el mar en peligro de muerte. De esta manera, el artículo 98 de la Convención de las Naciones Unidas para el Derecho del Mar establece:

1. Todo Estado exigirá al capitán de un buque que enarbole su pabellón que, siempre que pueda hacerlo sin grave peligro para el buque, su tripulación o sus pasajeros:

a) Preste auxilio a toda persona que se encuentre en peligro de desaparecer en el mar;

b) Se dirija a toda velocidad posible a prestar auxilio a las personas que estén en peligro, en cuanto sepa que necesitan socorro y siempre que tenga una posibilidad razonable de hacerlo, y

c) En caso de abordaje, preste auxilio al otro buque, a su tripulación y a sus pasajeros y, cuando sea posible, comunique al otro buque el nombre del suyo, su puerto de registro y el puerto más próximo en que hará escala.

2. Todo Estado ribereño fomentará la creación, el funcionamiento y el mantenimiento de un servicio de búsqueda y salvamento adecuado y eficaz para garantizar la seguridad marítima y aérea y, cuando las circunstancias lo exijan, cooperará para ello con los Estados vecinos mediante acuerdos mutuos regionales.

Como puede verse, la Convención de las Naciones Unidas sigue las viejas reglas de las "leyes del mar", aunque en este caso, legalmente objetivadas. No puede haber ninguna distinción en esta tarea de rescate. Por tanto, es independiente del lugar en el que la embarcación por rescatar se encuentre, de dónde son los náufragos, si tiene una bandera o no, o si el buque está en peligro o si la

\footnotetext{
${ }^{8}$ España se unió el 17 de noviembre de 1923.
} 
tripulación o los náufragos carecen de nacionalidad. Lo que es importante, por tanto, es el deber de rescatarlos por razones humanitarias.

Obviamente, esto plantea el problema jurídico del destino de los rescatados, incluyendo los posibles delincuentes y su situación legal. Por un lado, hay que tener en cuenta si el buque enarbola una bandera. Si este es el caso, sería el país al que corresponde la bandera ejercer su competencia jurisdiccional. Sin embargo, en la mayoría de los casos de migrantes, se trata de pateras, cayucos, balsas de goma que, en teoría, carecen de cualquier nacionalidad.

Sobre este tema, se podría decir que el Estado del pabellón del barco de rescate sería competente para sancionar a los que cometan un delito contra el tráfico de personas. Sin embargo, considero que es bastante complicado clasificar a los inmigrantes como irregulares, dado que también son víctimas del delito de tráfico de personas.

¿Cómo vamos a clasificar como indocumentado o "irregular" a quien no ha alcanzado el territorio de un Estado, ya que es un naufragio de un buque de otra nacionalidad o de una embarcación sin nacionalidad? ¿Se le debería llevar al puerto más cercano o a un puerto de la nacionalidad del buque que rescata?

Uno de los ejemplos más cercanos de esta situación se vio recientemente cuando un buque español, el remolcador Montfalcó, rescató a veintiséis africanos subsaharianos en el mar Mediterráneo. Debido a la negativa de Malta y a la negativa de Libia para hacerse cargo de las víctimas del naufragio, el buque de salvamento marítimo Clara Campoamor los recogió en el sur de Cerdeña para desembarcarlos en Tarragona. ${ }^{9}$

El problema radica en la interpretación de la norma. ¿Estamos ante una obligación de Malta y Libia para asumir a las víctimas de un naufragio o el Estado del pabellón del buque que rescata tiene que hacerse cargo de ello? Después será el momento de responsabilizarse de ellos, si deben ser tratados como inmigrantes irregulares. Esto es, devolverlos si es posible, o emitir una orden de expulsión.

La respuesta no es fácil, aunque en la práctica éste es el comportamiento que se sigue normalmente. Los Estados ribereños de la zona de alta mar donde se rescaten a los náufragos no tienen ninguna obligación de recibirlos, a menos que su vida o integridad física esté en riesgo. Sería, en mi opinión, diferente si su vida o su integridad estuvieran en peligro como resultado de una enfermedad, un accidente o trauma. En ese caso, el puerto más cercano debe aceptarlos.

\footnotetext{
9 BÁrbulo, TomÁs, "El barco de salvamento navega con los náufragos de Malta a Tarragona", El País, 1 de junio, 2007. Disponible en: http://elpais.com/diario/2007/06/01/espana/1180648820_850215.html
} 
El ACnuR, a través de las conclusiones de su Comité Ejecutivo ${ }^{10}$ y de un grupo de expertos reunidos en Lisboa, en 2002, consideró que los Estados costeros vecinos del rescate son los responsables de su admisión. ${ }^{11}$ Sin embargo, esta idea no se corresponde ni con el derecho convencional internacional ni con la práctica seguida de los Estados.

La práctica también nos muestra que el tratamiento que los náufragos terminan recibiendo en el país de destino es el de los inmigrantes irregulares. El caso extremo es, por ejemplo, el de un náufrago que no busca llegar irregularmente a la costa española, sino que está en el mar por ocio o trabajo. Esto sucedió en el caso de un joven marroquí, Mohamed D., que fue rescatado con un compañero de viaje por un buque mercante en aguas internacionales, después de 32 días a la deriva.

Al llegar al puerto, fue detenido por la policía y llevado ante los tribunales por una orden de expulsión y, mientras tanto, fue llevado a un centro de detención de extranjeros. La justificación legal no era que el joven trataba de entrar ilegalmente a España, sino que su estancia en España era ilegal. ${ }^{12}$

Por supuesto, los responsables del delito de tráfico de personas pueden ser castigados penalmente porque los tribunales pueden declararse competentes para conocer el caso, aunque el delito se haya cometido en alta mar a bordo de un buque sin nacionalidad.

\section{Obligación de los Estados de respetar a los migrantes}

El problema no es el acceso individual de los inmigrantes a las fronteras marítimas de Europa, sino el flujo masivo. Ahora bien, el flujo masivo (mass flow) es un concepto más restrictivo que la afluencia masiva (massive influx) de inmigrantes. Esto no es exactamente el mismo problema, pero ambos casos requieren el mismo trato ante la ley. El flujo masivo se puede producir por causas relacionadas con conflictos armados o la violación masiva de los derechos humanos u otras causas. ${ }^{13}$ Por lo tanto, podría responder a la aplicación de diferentes derechos y obligaciones.

\footnotetext{
${ }^{10}$ Conclusiones del Comité Ejecutivo de ACNUR no 14(1979), par. c; no 15 (1979), par. C; no 23 (1981), para. 3

"UNHCR, Background Note On The Protection Of Asylum-Seekers And Refugees Rescued At Sea, Lisboa, 2002.

12 Pérez, Laura, "Tratan como ilegal a uno de los náufragos llegados a la isla", La Opinión. Disponible en: http://www. laopinion.es/secciones/noticia.jsp?pRef=2009032600_9_208814_Sociedad-Tratan-como-ilegal-naufragos-Ilegados-Isla

${ }^{13}$ Arenas, Nuria, "The concept of 'Mass Influx of Displaced Persons' in the European Directive Establishing the Temporary Protection System", EIL, 2005, pp. 447 y ss.
} 
Un éxodo no sólo se presenta cuando hay conflictos armados. Cuando llega una marea humana a una frontera, por cualquier tipo de causa (clima, catástrofes naturales, industriales, economía, el Estado receptor no tiene más opción que permitir la llegada masiva por motivos humanitarios y darle, prima facie, una protección general a todos los que llegan. Asimismo el Estado receptor se ve obligado a garantizar los derechos humanos básicos a los inmigrantes, dado que la identificación individual es impracticable.

En este sentido, el Comité Ejecutivo de ACnuR, en 1981, indicó que los solicitantes de asilo en un éxodo que busquen refugio en un Estado, vecino o no, deben ser admitidos, al menos de forma temporal y se les debe proveer de protección acorde con los principios del derecho de refugiados. Todo ello sin discriminación alguna y sin devolverlos al lugar de origen donde puedan sufrir persecución (non-refoulement). ${ }^{14}$

La naturaleza jurídica de este principio ha sido calificada - de forma exagerada- como norma de ius cogens ${ }^{15}$, y yo mismo la he calificado de principio. ${ }^{16}$ O'brien ha estudiado la aplicación de esta norma, de forma extraterritorial, en la alta mar. ${ }^{17}$

En todo caso, este mínimo trato humanitario ya estaba previsto en la propia Convención sobre el Estatuto del Refugiado de $1951 .{ }^{18} \mathrm{Su}$ artículo 31 establece la obligación de los Estados a no imponer sanciones a las personas que, llegando directamente del territorio donde su vida o su libertad estuvieran amenazadas, aunque entren ilegalmente en el país. Los Estados deberán comprometerse a su vez a no hacer restricciones de circulación más que las necesarias y a facilitar todo lo necesario para obtener su admisión en otro país si en aquel no fuera posible.

De momento, la atención humanitaria, con la ayuda de diversos organismos en el mundo, principalmente ACNUR, sea cual sea la causa de la migración masiva en el Estado de que se trate, es el mínimo necesario y, por añadidura,

\footnotetext{
${ }^{14}$ Conclusiones del Comité Ejecutivo, núm 22 (32), 1981, p. 1.

${ }^{15}$ AlLaIn, JeAN, "The jus cogens Nature of non-refoulement", International Journal of refugee Law, vol. 13, núm. 4, 2001, pp. 533-558.

${ }^{16}$ Fernández Sánchez, Pablo Antonio, "The principle of non-refoulement of refugees in situations of armed conflict or occupation", International Conference on Refugees and International Law: the Challenge of Protection Refugee Studies Center. Disponible en: http://webcache.googleusercontent.com/search?q=cache:rX6F6RjAwloJ:http:// repository.forcedmigration.org/pdf/?pid\%3Dfmo:5369\%2Bpablo+antonio+fernandez+sanchez,+non+refoulementEthl $=$ es\&tgbv $=2 \& c t=c l n k$

${ }^{17}$ O'Brien, KILlan, "Refugees on the High Seas: Internatiional Refugee Law Solutions to a Law of the Sea Problem", Goettingen Journal of International Law, vol. 3, 2011, pp. 727- 729.

${ }^{18}$ ACNUR, "Convención sobre el estatuto de los refugiados". Disponible en: http://www.acnur.org/t3/fileadmin/scripts/ doc.php?file=t3/fileadmin/Documentos/BDL/2001/0005
} 
en el marco europeo, una protección temporal hasta que los casos individuales sean resueltos.

En el marco de la afluencia masiva, como consecuencia de un conflicto armado o violencia generalizada en el lugar de origen, los Estados tienen el derecho a desarmar a los que vengan armados, uniformados o no, y a separarlos a primera vista para evitar peligros a la población civil. Pero tienen la obligación de no devolverlos a un lugar donde su vida o integridad puedan estar en peligro. Esto es un elemento muy importante dado que se ha hablado mucho sobre la infiltración de elementos, si no armados, sí con intenciones de desestabilizar.

Por otra parte, imaginemos que se trata de una afluencia masiva de personas que huyen de la violencia generada en su territorio a un Estado vecino, que no es beligerante en el conflicto. Por tanto, hay un país, al menos, de tránsito, como podría ser Turquía. La fuente de las obligaciones en este caso es diferente, pero la base es la misma: el carácter humanitario y civil de los refugiados.

Por último, imaginemos que el flujo masivo ocurre en el territorio de un Estado donde hay facciones enfrentadas. Este caso difiere sustancialmente de las normas aplicables porque las normas aplicables a los conflictos internos son diferentes a las que rigen los conflictos armados internacionales.

Además, las dificultades son mayores porque los actores de la guerra son los movimientos insurgentes, grupos o bandas rebeldes, frente a los ejércitos regulares, y tienen un nivel más limitado de las propias obligaciones internacionales del Estado. Éste sería el caso de Siria, incluso de Afganistán e Irak.

De cualquier manera, se ha generado una costumbre internacional de dar refugio a las personas que llegan en flujos masivos, por la imposibilidad de identificar a cada una de las personas que llegan, por la aparente realidad y las circunstancias del país de origen. De esta manera, un grupo humano procedente de Afganistán, Siria o Irak, que en estos momentos huye de los bombardeos y de las durísimas circunstancias de un país en guerra, son objetivamente "desplazados forzosos" y merecen, por parte de la comunidad internacional, protección y asistencia.

120 Por ello, son personas concernientes a ACNUR y están incluidas en su mandato. Así, se genera la obligación de aceptar su admisión para darles seguridad, protegerles del refoulement y otorgarles un tratamiento básico humanitario acorde con las necesidades. ${ }^{19}$ Sin embargo, hay dificultades de delimitación de conceptos y de estatutos jurídicos que requerirían clarificación. ${ }^{20}$

\footnotetext{
${ }^{19}$ ACNUR, "Protection of Refugees in Mass Influx Situations: Over all Protection Framework", 19 de febrero, 2001.

${ }^{20}$ Albert, Mattews, "Governance and Prima Facie Refugee Status Determination: Clarifying the Boundaries of Temporary Protection, Group Determination, and Mass Influx", Refugee Survey Quarterly, vol. 29, núm. 1, 2010.
} 
Además de los ya mencionados derechos del artículo 31 de la Convención, el Comité Ejecutivo de ACNUR ha entendido un mínimo de derechos humanos que deben ser respetados: el disfrute de los derechos fundamentales reconocidos internacionalmente, en particular los reconocidos en la Declaración Universal de Derechos Humanos; la asistencia necesaria para el desarrollo de la vida, contando aquí con la debida solidaridad de otros Estados; el acceso a la justicia; la localización en zonas de seguridad donde la vida de los solicitantes o su integridad física o psíquica no peligre y donde no puedan llevar a cabo actividades subversivas contra su país de origen u otro Estado y otros derechos relacionados con la vida de familia, con soluciones duraderas o repatriación voluntaria. ${ }^{21}$

Tal como reconoce la normativa española, a modo de ejemplo, ${ }^{22}$ las personas que como consecuencia de conflictos o disturbios graves de carácter político, étnico o religioso, se hayan visto obligadas a abandonar su país, tienen derecho a permanecer en territorio nacional. Al menos esta norma les protege de la devolución y les garantiza el derecho mínimo de permanencia en el país, aunque no le extienda el resto de derechos de los refugiados.

¿Es esto lo que se está produciendo en la llamada crisis de los refugiados sirios? ¿Son sirios todos los que llegan? ¿Son solicitantes de asilo en los términos de la Convención de Ginebra de 1951? ¿Qué está haciendo la Unión Europea?

Por otro lado, la UE no sólo afronta el problema de la afluencia masiva de desplazados sirios, afganos e iraquíes en las costas de Grecia. Simultáneamente, afronta el problema del flujo masivo de inmigrantes que proceden generalmente de Libia, lugar a donde llegan desde las zonas centroafricanas. Todo esto se presente frecuentemente como consecuencia del tráfico de personas. ¿Cómo afrontar estos problemas con la humanidad que requiere la situación?

\section{Respuestas precarias ante la afluencia masiva de desplazados}

Con la gran crisis de los náufragos del 19 de abril de 2015, el caso sirio se ha estudiado especialmente en relación con la afluencia masiva de refugiados en Turquía (1.7 millones de desplazados), Jordania, Líbano (1.8 millones de desplazados) e Irak. La UE se ha centrado en dar algunas respuestas.

\footnotetext{
${ }^{21}$ Albert, MatTews, "Governance and Prima Facie Refugee Status Determination: Clarifying the Boundaries of Temporary Protection, Group Determination, and Mass Influx", Refugee Survey Quarterly, vol. 29, núm. 1, 2010.

${ }^{22}$ España dispone de una ley que prácticamente elimina la figura del asilado, limitándose a la restrictiva del refugiado.
} 
Para ellos, hay respuestas humanitarias, basadas en el derecho internacional. ${ }^{23}$ De hecho, como reconoce Goodwin Gill, hay normas del derecho de los refugiados, de derechos humanos, de derecho internacional humanitario y consideraciones elementales de humanidad ${ }^{24}$ que serían aplicables.

¿Cuáles serían los derechos y las obligaciones del Estado protector en cuanto territorio de asilo? De momento, al ser masivo el flujo migratorio, el Estado en cuestión tendrá la obligación mínima de darle una atención humanitaria - con ayuda de las distintas agencias humanitarias del mundo, primordialmente el ACNUR- y una protección temporal a los inmigrantes, hasta que puedan resolverse los casos individuales.

Pronto se vio el fracaso del sistema de protección europeo porque el Reglamento Dublín III sólo permite a un único Estado miembro analizar la solicitud presentada y ese debe ser, prima facie, el primer Estado por donde se haya cruzado la frontera exterior, independientemente de su regularidad. ${ }^{25}$ Grecia e Italia están físicamente incapacitadas para ello. La diferencia entre unos Estados y otros es abismal; los estatutos concedidos son también diferentes en cada Estado.

Para resolver, en parte, los problemas derivados de la imposibilidad de identificar y tramitar las solicitudes individuales de las personas llegadas a las costas griegas o italianas, se han establecido programas de reasentamiento, a través de la llamada solidaridad intracomunitaria.

España solía hacer acuerdos de reasentamientos con el ACNUR, pero no disponía de normativa específica para ello. Al modificarse la vieja Ley reguladora del derecho de asilo y la protección subsidiaria, la nueva Disposición Adicional I ya contempla la obligación de acordar este tipo de reasentamientos. ${ }^{26}$

Sin embargo, en la actual crisis de refugiados sirios, lo lógico hubiera sido poner en marcha el sistema de protección temporal existente en la UE. En su lugar, ¿qué ha hecho la Unión al respecto? El Consejo Europeo adoptó la Agenda

\footnotetext{
${ }^{23}$ Long, KatY, "In Search of Sanctuary: Border Closures, 'Safe' Zones and Refugee Protection", Journal of Refugee Studies, vol. 26, núm. 3, 2013, pp. 458-476.

${ }^{24}$ Feller, ERIKA, "The Refugee Convention at 60: still fit for purpose? Protection tolos for protection needs", en Susan Kneebone, Dallal Stevens \& Loretta Baldass (eds.), Refugee Protection and rthe Role of Law: Conflicting Identities, Nueva York, Routledges, 2014, p. 63.

${ }^{25}$ El artículo 3 del Reglamento Dublín III señala lo siguiente: "Los Estados miembros examinarán toda solicitud de protección internacional presentada por un nacional de un tercer pais o un apátrida, ya sea en el territorio de cualquiera de ellos, incluida la frontera, o en las zonas de tránsito. La solicitud será examinada por un solo Estado miembro, que será aquel que los criterios mencionados en el capitulo III designen como responsable".

${ }^{26}$ Ley $12 / 2009$ de 30 de octubre reguladora del derecho de asilo y la protección subsidiaria. BOE, núm. 263, de 31 de octubre, 2009.
} 
Europea para la Migración, reconociendo el fracaso de las respuestas europeas a la afluencia masiva de refugiados, principalmente de Siria. Las medidas inmediatas adoptadas fueron las siguientes:

i) medidas operativas

ii) apoyo presupuestario

iii) aplicación del Derecho de la Unión y la acción exterior, por ejemplo:

1. Triplicar la capacidad y los medios de las operaciones conjuntas de la Agencia Frontex (Tritón y Poseidón), en 2015 y 2016.

2. Activar el sistema de emergencia con arreglo al artículo 78, apartado 3 del Tratado de distribuir mejor los solicitantes de asilo en Europa.

3. Crear "puntos calientes", coordinados por la Comisión, donde la Agencia Europea de Apoyo al Asilo (EASo), Frontex y Europol puedan trabajar sobre el terreno para identificar, registrar y tomar huellas dactilares de los migrantes tan pronto como sea posible, así como coordinar el regreso.

4. Movilizar adicionalmente 60 millones de euros para financiar las necesidades urgentes.

5. Tener un programa de reasentamiento con un presupuesto de 50 millones de euros, destinados a transferir 20000 personas a Europa de forma segura y legal.

6. Asignación de 30 millones de euros para el desarrollo regional y los programas de protección empezando con el norte de África y el cuerno de África en 2015 y 2016.

7. Recopilar información mediante la colaboración de Europol con otras agencias europeas para desmantelar las redes criminales.

8. Establecer las operaciones europeas en el Mediterráneo con la captura y destrucción de las embarcaciones e incluir componentes migratorios en operaciones de gestión de crisis internacional ya desplegada en Níger y Mali.

9. Establecer un centro piloto de usos múltiples en Níger, en colaboración con la oIM y el ACNUR.

10. Desplegar agentes de inmigración europeas en las delegaciones de la UE en los países claves de tránsito. ${ }^{27}$

\footnotetext{
${ }^{27}$ Comisión Europea. Agenda Europea de Migración. COM (2015) 240 final, 13.05.2015.
} 
Aun así, se ha demostrado poco eficaz, porque los Estados se han estado ocupando más de sus opiniones públicas o de sus procesos electorales, que de sus obligaciones. La UE se había dotado de una normativa específica para los casos de afluencia masiva, basada en el precedente de la crisis de los Balcanes. Las consecuencias del conflicto de la ex Yugoslavia fueron los desencadenantes de este interés de la Unión Europea.

Esta "protección temporal" no es sólo una norma consuetudinaria internacional, como ya en 1988 reconocía Fitzpatrick, ${ }^{28}$ sino que ya tiene rangos más positivos porque ha sido incorporada al derecho de la Unión Europea y al ordenamiento jurídico de sus Estados miembro, entre ellos, España. ${ }^{29}$

Como vemos, estas situaciones están reguladas pero, aunque los Estados europeos no son los únicos, cierran las puertas a las personas desplazadas, mientras critican a aquellos Estados menos desarrollados. Sobre todo critican a los Estados de África, pues no pueden soportar el gasto y la presión demográfica que suponen estos millones de desplazados.

Todo ello es porque el derecho de los refugiados en Europa no responde a la realidad social de nuestros días y, cuando responde técnicamente, no responde en la práctica. De los más de 60 millones de desplazados forzados que hay en el mundo, Europa, junto con los Estados Unidos, sólo soporta 10\%: los países menos desarrollados, los que mayor carga sostienen. Por tanto, su contribución al problema de los refugiados es ínfima en comparación con la generosidad de los países menos desarrollados.

Incluso en África existe un instrumento jurídico que trata de solucionar este problema de los desplazados. Es la Convención de la ouA relativa a Aspectos Específicos de los Problemas de los Refugiados en África, de 10 de septiembre de 1969.

América Latina también ha reflexionado sobre los desplazados masivos y la Asamblea General de la Organización de Estados Americanos aprobó una Resolución el día 6 de junio de 1991 en la cual felicitaba a los Estados miembro la aceptación de los principios contenidos en la Declaración de Cartagena. Esto

124 es la aceptación de que los desplazados masivos tienen derecho también al estatuto jurídico de refugiado y por tanto a la protección internacional.

\footnotetext{
${ }^{28}$ FitzPATRICK, JoAn, "The Principle and Practice of Temporary Refugee: A Customary Norm Protecting Civilian Fleeing Internal Armed Conflict", en David Martin (ed.), The New Asylum Seekers: refugee Law in the 1980's, Londres, Martinus Nijhoff Publishers, 1988, pp. 87-121.

${ }^{29}$ Real Decreto 1325/2003, de 24 de octubre, por el que se aprueba el Reglamento sobre régimen de protección temporal en caso de afluencia masiva de personas desplazadas.
} 
Por ello, La Unión Europea ha desarrollado una directiva que establece normas comunes para todos los Estados miembro: la concesión de una protección temporal a las personas que huyan de sus países en caso de afluencia masiva de personas desplazadas en la Unión Europea. ${ }^{30}$ Todos los Estados europeos han procedido a su trasposición en su ordenamiento interno o resulta ya de trasposición directa y automática.

Sin embargo, aunque en la actual crisis de los refugiados sirios se suponía que los Estados europeos debían implementar el sistema existente de protección temporal en la UE, no se ha puesto en marcha este sistema. ¿Por qué no se ha puesto en marcha? En la opinión de Arenas la directiva de protección temporal es de gran importancia, pues se acerca a la idea de que la decisión de acoger en caso de afluencia masiva debe ser vinculante. Pero la directiva no establece criterios para la asignación de las personas que quedan finalmente a merced de la capacidad de acogida de cada Estado.

El concepto de personas beneficiarias de protección temporal es bastante amplio. Hoy, quedarían superados los grupos que la Unión Europea haya determinado como beneficiarios de protección internacional; el Estado también da bastante garantía y el sistema lo somete a una doble voluntariedad -a la voluntad del Estado miembro de acogida y el consentimiento del beneficiario-. De este modo, no es de extrañar que este instrumento nunca se haya utilizado. ${ }^{31}$

Ningún Estado miembro de la UE lo ha solicitado, ni la Comisión Europea ha constatado formalmente una afluencia masiva que requiera protección temporal. En términos políticos puede explicarse por qué la directiva de protección temporal es muy "generosa". Exige la voluntad de las personas para ser acogidas en un territorio - casi todos quieren instalarse en Alemania o Estados del norte de Europa, por sus sistema de protección-.

Por otro lado, la directiva autoriza a los beneficiarios a residir legalmente, ejercer una actividad retribuida, a acceder a un alojamiento adecuado, recibir asistencia y ayuda social, acceder al sistema educativo, a la reagrupación familiar, e incluso a solicitar individualmente el asilo. Igualmente, convienen los plazos de las ayudas para el regreso voluntario y las condiciones limitadas para el regreso forzoso. Todo ello explica, aunque no justifica, que los Estados no hayan querido activar el sistema.

\footnotetext{
${ }^{30}$ Directiva 2001/55/CE del Consejo, de 20 de julio de 2001, relativa a las normas mínimas para la concesión de protección temporal en caso de afluencia masiva de personas desplazadas y a medidas de fomento de un esfuerzo equitativo entre los Estados miembro para acoger a dichas personas y asumir las consecuencias de su acogida.

${ }^{31}$ Arenas Hidalgo, Nuria de la Cinta, "Flujos masivos de población y seguridad. La crisis de personas refugiadas en el Mediterráneo", Araucaria, vol. 18, núm. 36, 2016, pp. 339-372.
} 
Por el contrario, la uE sí ha activado el sistema de emergencia, establecido en el Tratado de Lisboa. El 78.3 Tratado de Funcionamiento de la Unión Europea (TFUE) señala que "En el caso de que uno o más Estados miembro se enfrenten a una situación de emergencia caracterizada por la llegada repentina de nacionales de terceros países, el Consejo, a propuesta de la Comisión, podrá adoptar las medidas provisionales en beneficio del Estado miembro de que se trate. Se pronunciará previa consulta al Parlamento Europeo".

Esta ha sido la base jurídica por la cual la Comisión Europea ha propuesto su activación de cuotas de desplazados o mecanismo de reubicación temporal. El Consejo Europeo ha decidido redistribuir a 40000 refugiados, hasta el 17 de septiembre de $2017,{ }^{32}$ y posteriormente a $120000 .^{33}$ A pesar de ello, mientras Finlandia se abstuvo, Hungría, República Checa, Eslovenia y Rumania votaron en contra de la decisión del Consejo Europeo, que es vinculante para todos los Estados miembro. ${ }^{34}$

El reparto se pondera en función de ciertas variables como el producto interno bruto de cada Estado, el número medio de solicitudes de asilo tratados en los cinco años anteriores, la tasa de desempleo, entre otras. ${ }^{35}$ Pero, como puede comprobarse, la carencia de infraestructuras en Italia y Grecia, el rechazo de los desplazados a ser registrados en esos dos países y la falta de voluntad política de los demás Estados siguen siendo grandes escollos.

\section{Flujo masivo por causas distintas a los conflictos armados}

La situación jurídica difiere en cuanto a la afluencia masiva de inmigrantes - principalmente procedentes de Libia- a las costas italianas, pero el tratamiento humanitario y el respeto de los derechos humanos sigue siendo su elemento esencial. Este flujo migratorio se debe, fundamentalmente, a la organización de las mafias que trafican con seres humanos, inicialmente con inmigrantes, aunque en muchos casos también con fines de explotación sexual.

Para estas cuestiones, el artículo 27 de la Convención contra la Delincuencia Organizada Transnacional obliga a los Estados parte a trabajar en estrecha colaboración para hacer cumplir la ley. Esto exige el intercambio de informa-

\footnotetext{
${ }^{32}$ Decisión 2015/1523 del Consejo, de 14 de septiembre de 2015.

${ }^{33}$ Decisión (UE) 2015/1601 del Consejo, de 22 de septiembre de 2015, por la que se establecen medidas provisionales en el ámbito de la protección internacional en beneficio de Italia y Grecia.

${ }^{34}$ AbelÁN, Lucia, "La UE acuerda reparto de 120000 refugiados con cuatro paises en contra", El País. Disponible en: http://internacional.elpais.com/internacional/2015/09/22/actualidad/1442936990_887494.html

${ }_{35}$ WolfF, SARAH, Migration and Refugee Governance in the Mediterranean: Europe and International Organizations at a Crossroads, Working Paper 15/42, Instituto Affari Internazionale, 2015.
} 
ción, la identificación de los criminales, la detección de los movimientos de mercancías y criminales y la ubicación de las víctimas y los testigos, lo cual debe incluir la cooperación marítima.

La necesidad de cooperación marítima para combatir la trata de personas y migrantes, en el marco europeo, conlleva algunas particularidades llamadas Schengen del mar. En este sentido, solamente voy a mencionar algunas de las iniciativas adoptadas en este marco europeo, conscientes de que el desarrollo de esta parte requeriría mucha mayor profundidad. Me limitaré a mencionar algunas de las medidas tomadas en el marco de la cooperación marítima internacional para luchar contra el tráfico ilícito de migrantes y para la protección de los derechos humanos.

La Unión Europea aprobó la Directiva 2002/90/CE del Consejo, de 28 de noviembre de 2002, sobre la definición de la ayuda a la entrada, a la circulación y residencia de los irregulares, y la Decisión marco del Consejo, de 28 de noviembre de 2002 para reforzar el marco penal para la represión de la entrada no autorizada, de tránsito y de residencia (2002/946/JAI).

El Consejo de ministros de Justicia e Interior del 25 y el 26 de abril de 2002 adoptó unas conclusiones sobre la inmigración ilegal y el tráfico de personas por vía marítima. Éstas condujeron al mismo Consejo, en su reunión del 13 de junio del 2002, a aprobar unas conclusiones sobre "medidas para prevenir y combatir la inmigración ilegal y el tráfico de seres humanos por el mar y en particular las medidas contra terceros Estados que no estén dispuestos a cooperar con la uE en la lucha contra la inmigración ilegal”. Las medidas previstas fueron las siguientes:

a) Las medidas operativas

- La cooperación sistemática entre los Estados miembro junto a operaciones conjuntas posibles para el control de las fronteras marítimas y buques sospechosos de transportar de manera ilegal seres humanos

- Aumento de la actividad de los funcionarios de enlace en los países de embarque, salida o tránsito de inmigrantes irregulares

- Mejora del sistema de alerta rápida

- Una mayor participación de Europol

- Creación de equipos conjuntos de investigación

- El uso de las medidas adecuadas para identificar los buques en zonas de riesgo 
- Consideración de las operaciones conjuntas o individuales de vigilancia marítima desde el aire

- Acción sobre la entrada ilegal, de tránsito y de residencia

b) Las medidas preventivas

- Firma, ratificación y aplicación de la Convención de las Naciones Unidas contra la Delincuencia Organizada Transnacional de diciembre de 2000, el Protocolo para Prevenir, Reprimir y Sancionar la Trata de Personas y el Protocolo contra el Tráfico Ilícito de Migrantes por Tierra, Mar y Aire y otros instrumentos internacionales pertinentes

- Penalizar en la legislación nacional el tráfico de seres humanos, incluyendo la confiscación de los barcos utilizados en este tráfico

- Imponer una conducta criminal con sanciones a la falsificación y el uso fraudulento de documentos de viaje

- Promover o facilitar la realización de campañas de información, que serán financiadas por la UE o sus Estados miembro.

- Aumentar el control de las fronteras del mar de barcos sospechosos de tráfico de seres humanos, que se complementen con un control policial dentro del territorio nacional.

- El fortalecimiento de las medidas de control en las fronteras, para impedir la entrada de personas que deseen utilizar el territorio de un tránsito ilegal a los Estados miembro de la UE, incluidas las posibles adaptaciones de sus sistemas de visa.

- La cooperación con los servicios de fronteras de Estados de la UE para el intercambio de información sobre los barcos sospechosos de tráfico ilegal de personas

- Expresar la voluntad a los países de origen o de tránsito de inmigrantes que entren en la uE por mar y cuya producción puede quedar adecuadamente demostrada de que los acepten las obligaciones de readmisión impuestas.

- Definir de manera urgente y clarificar las zonas marítimas que cada país tiene para ejercer sus propias competencias de búsqueda y rescate ${ }^{36}$ 
Pero tal vez la medida más espectacular de la cooperación europea en la lucha contra la trata y el tráfico de inmigrantes ha sido la creación de una Agencia Europea para la Gestión de la Cooperación Operativa en las Fronteras Exteriores (Frontex). ${ }^{37}$ Finalmente, fue aprobada por el Reglamento (CE) $n^{\circ}$ $2007 / 2004$ de 26 de octubre. ${ }^{38}$

El problema no se plantea en lo que respecta a los responsables penales del tráfico de personas, como los traficantes, sino más bien en la condición jurídica de los traficados, como víctimas. Tradicionalmente, como hemos visto, son tratados como inmigrantes irregulares aunque no hayan entrado ilegalmente en un Estado.

Sin embargo, hay fórmulas que ofrece la normativa de la Unión Europea como, por ejemplo, la aplicación de la Directiva 2004/81/CE, del 29 de abril de 2004, sobre el permiso de residencia a nacionales de terceros países que sean víctimas de la trata de seres humanos o hayan sido objeto de ayuda a la inmigración ilegal, que cooperen con las autoridades competentes. ${ }^{39}$

Por supuesto, como se indica en los considerandos 4 del preámbulo de esta Directiva, "La presente Directiva se entiende sin perjuicio de la protección concedida a los refugiados, a los beneficiarios de protección subsidiaria y las personas que buscan protección internacional en virtud del derecho internacional de los refugiados y sin perjuicio de otros instrumentos de derechos humanos".

Ahora bien, si esto puede ser relativamente fácil en casos particulares y aislados, es mucho más complejo cuando hay un sistema criminal que lanza al mar a miles de personas, de quienes se han beneficiado económicamente y las abandonan en una balsa de plástico. Así, estas personas quedan hacinadas en un bote de plástico o un vetusto barco pesquero, con poco combustible y sometidas a los vaivenes de una mar casi siempre desconocida por las víctimas. Y cuando las costas desde donde salen están no sólo mal protegidas, sino que son ingobernables, la situación se hace mucho más difícil.

Este es el caso de Libia, desde donde miles de inmigrantes son lanzados al mar, sin el más mínimo escrúpulo. Por ello, el Estado europeo más próximo, Italia, organizó una operación, llamada Mare Nostrum, para tratar de salvar miles de vidas ${ }^{40}$ y para salvaguardar su propia imagen de Estado que abandona

\footnotetext{
${ }^{37}$ Doc. COM/2003/0687 final - CNS, 2003/0273.

${ }^{38}$ DOCE $\mathrm{L} 349$ de 25 de noviembre, 2004, pp. 1-11.

${ }^{39}$ DO L261, of 6th August 2004.

${ }^{40}$ Marina Militare, "Mare Nostrum Operation", Ministero Della Difesa. Disponible en: http://www.marina.difesa.it/EN/ operations/Pagine/MareNostrum.aspx
} 
sus obligaciones. Esto después de que incluso el papa Francisco le criticara y calificara la situación de vergüenza. ${ }^{41}$

Sin embargo, esa operación estrictamente italiana no fue suficiente y tras el terrible naufragio de más de quinientas personas, la uE se sensibilizó y planeó la Operación Tritón. ${ }^{42}$ Ésta dependía de Frontex para que encabezara las tareas de búsqueda y salvamento en el área mediterránea. Ahora bien, la Operación Tritón, con la participación de veintiún Estados contó con un presupuesto inicial de tres millones de euros, una tercera parte de los nueve mensuales que costaba a Italia sólo la Operación Mare Nostrum.

Además, se ha criticado que la Operación Tritón sólo operaba en espacios marinos italianos, mientras que la Operación Mare Nostrum italiana ya operaba en todo el Mediterráneo. ${ }^{43}$ Es verdad que luego se han extendido tanto sus recursos como su área operativa pero, definitivamente, no era una operación de salvamento y rescate.

Finalmente, la Unión Europea necesitó desplegar una operación que tuviera al menos ese doble carácter de alterar el modelo criminal del tráfico de personas y de contribuir a reducir la pérdida de vidas humanas. Para ello, el Consejo de la UE adoptó la Decisión de la Política Exterior y de Seguridad Común (PESC) 2015/778 del consejo de 18 de mayo de 2015, relativa a una operación militar de la Unión Europea en el Mediterráneo central meridional, conocida como Operación Sophia.

$\mathrm{Su}$ despliegue se ha hecho en tres fases porque había que implementar la correspondiente autorización del Consejo de Seguridad para poder operar en espacios de alta mar, a los efectos de la navegación, frente a las costas de Libia. La primera fase tuvo lugar entre el 22 de junio y el 6 de octubre de 2015, para apoyar la detección y el seguimiento de las redes de migración mediante la recopilación de información y las patrullas en alta mar de conformidad con el derecho internacional.

La segunda fase (a partir del 7 de octubre de 2015) tuvo como misión la visita, el registro, el apresamiento y el desvío en alta mar de los buques sospechosos de ser utilizados para el tráfico ilícito o la trata de seres humanos, en las condiciones previstas en el derecho internacional aplicable.

\footnotetext{
${ }^{41}$ Ordaz, Pablo, "El papa: 'Es una vergüenza'", El País, 3 de octubre, 2013. Disponible en: http://internacional.elpais. com/internacional/2013/10/03/actualidad/1380815118_506650.html

${ }^{42}$ Grasso, Daniele, "¿Qué hace Europa ante las tragedias de la inmigración? De Mare Nostrum a Tritón", El Confidencial, 21 de abril, 2015. Disponible en: http://www.elconfidencial.com/mundo/2015-04-21/de-mare-nostrum-a-triton-cambiar-de-estrategia-para-que-todo-siga-igual_763373/

${ }^{43}$ Hubo otra operación temporal de Frontex, la llamada Operación Poseidón, que tenía como misión principal el control de los flujos migratorios organizados por redes criminales.
} 
Igualmente y de conformidad con cualquier resolución aplicable del Consejo de Seguridad de las Naciones Unidas o el consentimiento del Estado ribereño, procederá a visitar, registrar, apresar y desviar, en alta mar y en las aguas de competencia de dicho Estado, los buques sospechosos de ser utilizados para el tráfico ilícito o la trata de seres humanos, en las condiciones establecidas en dicha resolución o consentimiento.

En la fase tres, incluso cuando haya resolución del Consejo de Seguridad o autorización del soberano territorial, adoptará todas las medidas necesarias, incluso la eliminación o inutilización, contra un buque y los medios relacionados que se sospeche que se utilizan para el tráfico ilícito o la trata de seres humanos, en el territorio de dicho Estado, en las condiciones establecidas en dicha resolución o consentimiento. ${ }^{44}$

La Operación Sophia se inició el 22 de junio de 2015 y ya está en la fase tres, por lo cual puede identificar, capturar y eliminar buques utilizados para el tráfico de personas. "Desde entonces, la operación ha contribuido a la detención y entrega a las autoridades italianas de 71 presuntos traficantes, y ha neutralizado 139 buques. Además, la operación ha ayudado a salvar más de 16000 vidas." 45

El Consejo de la UE, el 20 de junio de 2016, prorrogó la Operación Sophia hasta el 27 de julio de 2017 y amplió su mandato a dos nuevas actividades: la formación de los guardacostas y de la Armada libia ${ }^{46}$ y la contribución a la ejecución del embargo de armas de las Naciones Unidas en alta mar frente a las costas libias. ${ }^{47}$

Esto ha sido posible debido a que el Consejo de Seguridad de Naciones Unidas ha podido adoptar la Resolución 2240 (2015) de 9 de octubre de 2015. Ésta permite apresar buques en alta mar, frente a las costas de Libia, cuando se sospeche que trafican con personas. Más adelante, se ampliaría esta vigilancia

\footnotetext{
${ }^{44}$ Arenas, NuRIA, "Flujos masivos de población y seguridad. La crisis de personas refugiadas en el Mediterráneo", Aracuaria, vol. 18, núm 36, 2016.

45 "Operación Eunavfor Med Sophia: el mandato prorrogado por un año, dos nuevas tareas", Consejo de la Unión Europea, 20 de junio, 2016. Disponible en: http://www.consilium.europa.eu/es/press/press-releases/2016/06/20-fac-eunavfor-med-sophia/

${ }^{46}$ Poltitical And Security Committee Decision (cFsp) 2016/1635 of 30 August 2016 on the commencement of the capacity building and training of the Libyan Coast Guard and Navy by the European Union military operation in the Southern Central Mediterranean (Eunavfor Med operation Sophia) (Eunavfor Med/3/2016, Doue L 243, de 1 de septiembre, 2016.

${ }^{47}$ Poltical And Security Commititee Decision (cFsp) 2016/1637 of 6 September 2016 on the commencement of the European Union military operation in the Southern Central Mediterranean (Eunavfor Med operation Sophia) contributing to the implementation of the un arms embargo on the high seas off the coast of Libya (Eunavfor Med/4/2016), DOUE $L$ 243, de 10 de septiembre, 2016.
} 
y apresamiento, con el objetivo también de vigilar el embargo de armas con destino o con origen en Libia. ${ }^{48}$

No podemos decir que la tarea principal de la Operación Sophia sea el rescate de las víctimas del tráfico de personas pero, sin duda, ha contribuido enormemente a reducir la pérdida de vidas humanas en el Mediterráneo central.

\section{Conclusiones}

El derecho del mar, sin pretenderlo, ha generado un nuevo tipo de fronteras a los efectos migratorios. Donde se establecieron competencias estatales, hoy, hay verdadero control fronterizo. De esta forma, los Estados ejercen control más allá de las aguas interiores y el mar territorial. En tales espacios los Estados ejercen competencias migratorias plenas, exclusivas e inviolables. En la zona contigua, dichas competencias son muy amplias. En alta mar, ejercen competencias de persecución en caliente e incluso de visita, si hay autorización del Estado del pabellón o del Consejo de Seguridad de Naciones Unidas.

La vieja ley del mar, que obliga a toda persona, buque o Estado, a salvaguardar la vida y la integridad de las personas náufragas, hoy está más vigente que nunca. No sólo porque hay todo un corpus iuris destinado al efecto, donde los servicios de salvamento marítimo estatales alcanzan espacios que van mucho más allá de los propios espacios marítimos estatales, sino porque se ejerce la jurisdicción penal estatal en tanto haya un elemento nacional. Éste elemento bien puede ser derivado de la nacionalidad de la víctima, del territorio donde se encuentre el responsable, de la aplicación del principio aut dedere aut judicare o del ejercicio de la jurisdicción universal.

Los Estados, en cualquier situación, incluso de conflicto armado, están obligados a respetar los derechos humanos de las personas que encuentren en el mar, independientemente del estatuto jurídico que pueda llegar a ostentar. Esto será así, incluso ante una afluencia masiva de personas. Ante un flujo masivo de personas, refugiados o desplazados, que huyen de un conflicto armado, la identificación individual pormenorizada es impracticable.

Por ello, se debe establecer prima facie, una protección temporal de estas personas. Una vez hayan accedido al Estado receptor, por los puestos fronterizos habilitados al efecto, el Estado receptor tiene la obligación de recibirlos (artículo 31 del Estatuto de Ginebra). Además, deberá darles la protección y la asistencia debida, con la ayuda de ACNUR y de la comunidad internacional. Ha-

\footnotetext{
${ }^{48}$ Resolución del Consejo de Seguridad 2292 (2016), de 14 de junio de 2016.
} 
brá de protegerlos a todos, como mínima compensación por devolverlos a su lugar de origen, donde su vida o su integridad pudieran estar en peligro (non refoulement). Esto con el tratamiento humanitario que se deriva de la protección general de los derechos humanos y del derecho internacional humanitario.

La Unión Europea padece una doble crisis migratoria. Por un lado, algunas personas huyen de un conflicto armado y, por otro, algunas personas huyen de sus países de origen como consecuencia de la hambruna, del cambio climático, de la violencia generalizada. Éstas se apoyan en redes de traficantes de personas para llegar a territorio europeo, ante la falta de canales menos peligrosos. Todo ello ha demostrado que el sistema de la Unión Europea es impracticable.

El modelo europeo no sirve porque carece de la voluntad política de los Estados de la uE para aplicarlo. Además, la cicatería europea en el compromiso de protección de los derechos de las personas que se ven forzadas a emigrar se limita a ayuda humanitaria. Esto conlleva una presión política y económica para que los Estados menos desarrollados carguen con todo el peso de esta situación y, a veces, paguen por esta carga.

La Unión Europea ni siquiera ha sido capaz de poner en marcha su propia normativa, en materia de protección temporal o de protección de las víctimas del tráfico de personas. Los europeos vivimos en una burbuja que nos impide acercarnos a los problemas reales de quienes sufren esas condiciones.

\section{Bibliografía}

Abellán, Lucí, "La ue acuerda reparto de 120000 refugiados con cuatro países en contra”, El País. Disponible en: http://internacional.elpais.com/internacional/2015/09/22/actualidad/1442936990 887494.html

ACNUR, “Convención sobre el estatuto de los refugiados". Disponible en: http://www. acnur.org/t3/fileadmin/scripts/doc.php?file=t3/fileadmin/Documentos/ $\mathrm{BDL} / 2001 / 0005$

ACNUR, "Protection of Refugees in Mass Influx Situations: Over all Protection Framework", 19 de febrero, 2001.

Albert, MatTews: "Governance and Prima Facie Refugee Status Determination: Clarifying the Boundaries of Temporary Protection, Group Determination, and Mass Influx”, Refugee Survey Quarterly, vol. 29, núm. 1, 2010.

Allain, JeAn, “The jus cogens Nature of non-refoulement”, International Journal of refugee Law, vol. 13, núm. 4, 2001.

ARenas, NuRIA, “The concept of 'Mass Influx of Displaced Persons' in the European Directive Establishing the Temporary Protection System”, EJI, 2005. 
ARENAS, NuRIA, "Flujos masivos de población y seguridad. La crisis de personas refugiadas en el Mediterráneo”, Araucaria, vol. 18, núm. 36, 2016.

BÁrbulo, TomÁs, "El barco de salvamento navega con los náufragos de Malta a Tarragona”, El Pais, 1 de junio, 2007. Disponible en: http://elpais.com/diario/2007/06/01/espana/1180648820_850215.html

Feller, ErIKA, "The Refugee Convention at 60: still fit for purpose? Protection tolos for protection needs", en Susan Kneebone, Dallal Stevens \& Loretta Baldass (eds.), Refugee Protection and rthe Role of Law: Conflicting Identities, Nueva York, Routledges, 2014.

Fernández SÁnchez, Pablo Antonio, "The principle of non-refoulement of refugees in situations of armed conflict or occupation", International Conference on Refugees and International Law: the Challenge of Protection Refugee Studies Center. Disponible en: http://webcache.googleusercontent.com/ search?q=cache:rX6F6RjAwIoJ:http://repository.forcedmigration.org/pdf/?pid\%3Dfmo:5369\%2Bpablo+antonio+fernandez+sanchez,+non+refoulementcthl=esEtgbv $=2 \mathrm{Ctct}=\mathrm{clnk}$

FitzPatrick, Joan, "The Principle and Practice of Temporary Refugee: A Customary Norm Protecting Civilian Fleeing Internal Armed Conflict”, en DAVID MARTIN (ed.), The New Asylum Seekers: refugee Law in the 1980's, Londres, Martinus Nijhoff Publishers, 1988.

Grasso, Daniele, “¿Qué hace Europa ante las tragedias de la inmigración? De Mare Nostrum a Tritón”, El Confidencial, 21 de abril, 2015. Disponible en: http:// www.elconfidencial.com/mundo/2015-04-21/de-mare-nostrum-a-tritoncambiar-de-estrategia-para-que-todo-siga-igual_763373/

LoNG, KaTY, "In Search of Sanctuary: Border Closures, 'Safe' Zones and Refugee Protection", Journal of Refugee Studies, vol. 26, núm. 3, 2013.

Marina Militare, "Mare Nostrum Operation", Ministero Della Difesa. Disponible en: http://www.marina.difesa.it/EN/operations/Pagine/MareNostrum.aspx

NaCIONES UnidAs, Guías Legislativas para la aplicación de la Convención de las Naciones Unidas contra la Delincuencia Organizada Transnacional y sus Protocolos, División para Asuntos de Tratados”, Estados Unidos, United Nations Publications, 2005.

0'BRIEn, Killian, "Refugees on the High Seas: Internatiional Refugee Law Solutions to a Law of the Sea Problem", Goettingen Journal of International Law, vol. 3, 2011.

"Operación Eunavfor Med Sophia: el mandato prorrogado por un año, dos nuevas tareas", Consejo de la Unión Europea, 20 de junio, 2016. Disponible en: http:// www.consilium.europa.eu/es/press/press-releases/2016/06/20-fac-eunavfor-med-sophia/

Ordaz, Pablo, “El papa: ‘Es una vergüenza’”, El País, 3 de octubre, 2013. Disponible en: http://internacional.elpais.com/internacional/2013/10/03/actualidad/1380815118_506650.html 
ORdAZ, PABlo, "Casi 3000 migrantes han muerto este año en el Mediterraneo”, El Pais, 26 de julio, 2016. Disponible en: http://internacional.elpais.com/internacional/2016/07/22/actualidad/1469184421_996319.html

Pastor Ridruejo, José Antonio, Curso de Derecho Internacional Público y Organizaciones Internacionales, Madrid, Tecnos, 2003.

PÉrez, LAURA, “Tratan como ilegal a uno de los náufragos llegados a la isla”, La Opinión. Disponible en: http://www.laopinion.es/secciones/noticia.jsp?pRef=2009032600_9_208814_Sociedad-Tratan-como-ilegal-naufragos-llegados-Isla

Political And Security Committee Decision (cFsp) 2016/1635 of 30 August 2016 on the commencement of the capacity building and training of the Libyan Coast Guard and Navy by the European Union military operation in the Southern Central Mediterranean (Eunavfor Med operation Sophia) (Eunavfor Med/3/2016), DouE L 243, de 1 de septiembre, 2016.

Political And Security Committee Decision (cFsp) 2016/1637 of 6 September 2016 on the commencement of the European Union military operation in the Southern Central Mediterranean (Eunavfor Med operation Sophia) contributing to the implementation of the UN arms embargo on the high seas off the coast of Libya (Eunavfor Med/4/2016), Doue L 243, de 10 de septiembre, 2016.

SAntos Vara, JuAn, “Crónica sobre la Aplicación Judicial del Derecho Internacional Público (enero-junio 2006)”, REEI, vol. 12, 2006.

unHCR, Background Note On The Protection Of Asylum-Seekers And Refugees Rescued At Sea, Lisboa, 2002.

WolfF, SARAH, Migration and Refugee Governance in the Mediterranean: Europe and International Organizations at a Crossroads, Working Paper 15/42, Instituto Affari Internazionale, 2015.

Yturriaga BarberÁn, José Antonio De, Ámbitos de soberania en la Convención de las Naciones Unidas sobre el Derecho del Mar: Una perspectiva española, Madrid, Ministerio de Asuntos Exteriores, 1993. 